\title{
Use of Clergy Services among Individuals Seeking Treatment for Alcohol Use Problems
}

\author{
Amy S.B. Bohnert, PhD, ${ }^{1,2}$ Brian E. Perron, PhD, ${ }^{1,3}$ Christopher N. Jarman, MSW, ${ }^{3}$ \\ Michael G. Vaughn, PhD, ${ }^{4,5,6}$ Linda M. Chatters, PhD, ${ }^{3,7}$ Robert Joseph Taylor, PhD ${ }^{3}$ \\ ${ }^{1}$ VA National Serious Mental IIIness Treatment Research Evaluation Center, Ann Arbor, Michigan \\ ${ }^{2}$ Department of Psychiatry, University of Michigan Medical School, Ann Arbor, Michigan \\ ${ }^{3}$ School of Social Work, University of Michigan, Ann Arbor, Michigan \\ ${ }^{4}$ School of Social Work, Saint Louis University, St. Louis, Missouri \\ ${ }^{5}$ Department of Epidemiology, School of Public Health, Saint Louis University, St. Louis, Missouri \\ ${ }^{6}$ Department of Public Policy Studies, College of Education and Public Service, Saint Louis University, St. Louis, Missouri \\ ${ }^{7}$ Department of Health Behavior and Health Education, University of Michigan, School of Public Health, Ann Arbor, Michigan
}

This study examined the prevalence and characteristics of adults with an alcohol use-related problem who receive clergy services. Data come from the National Epidemiologic Survey on Alcohol and Related Conditions. Among persons who sought any services for alcohol-related problems $(n=1,910)$, $14.7 \%$ reported using clergy services. In a multivariable logistic regression model, factors associated with increased likelihood of service use included being Black, aged 35-54 years, a lifetime history of alcohol dependence, major depressive disorder, and personality disorder. Clergy may benefit from training to identify alcohol use problems and serve an important role in making treatment referrals. (Am J Addict 2010;19:345-351)

\section{BACKGROUND}

Problematic alcohol use includes patterns of excessive use, such as heavy drinking ${ }^{1}$ and binge drinking, ${ }^{2}$ as well as psychological conditions, operationalized in the Diagnostic and Statistical Manual of Mental Disorders (DSM) as alcohol use disorders (AUDs). ${ }^{3}$ Collectively, these patterns of alcohol misuse and psychological conditions due to alcohol misuse have been linked to a wide variety of negative social and health outcomes. ${ }^{4-11}$ Effective treatments for alcohol misuse exist. ${ }^{12,13}$ However, among adults with an AUD, only one quarter receive treatment. ${ }^{13}$ The average

Received August 19, 2009; revised September 12, 2009; accepted October 29, 2009.

Address correspondence to Dr. Bohnert, VA National Serious Mental Illness Treatment Research Evaluation Center, Ann Arbor SMITREC (11H), 2215 Fuller Road, Ann Arbor, MI 48105. E-mail: amybohne@med.umich.edu. time between onset of an alcohol use disorder and subsequent treatment is typically more than 10 years. ${ }^{14}$

A variety of factors contribute to the low rates of treatment and long delays among adults with problematic alcohol use. Treatment-related barriers include concerns about cost, lack of insurance, and difficulty accessing treatment. ${ }^{15}$ In addition, social and psychological barriers to alcohol treatment include denial, stigma, guilt, and ignorance about treatment options. ${ }^{16}$ Reducing these barriers is critical. Making initial contact with a treatment provider is an essential first step toward recovery. Individuals with an AUD who receive treatment are often referred from other treatment settings, including primary care providers and mental health providers. Others enter treatment through coercion by the criminal justice system or pressures from family members. Understanding the correlates of AUD treatment is essential to understanding how to reduce barriers to care.

One type of service or support that may hold potential for reducing barriers and increasing engagement in the treatment process for persons with AUDs is churches and other religious community organizations. ${ }^{17}$ In many communities, churches are important sources of social support by virtue of their involvement in activities as varied as economic and community development, political and civic issues, education, and social networks. ${ }^{18,19}$ This appears to be particularly true in African American communities; approximately $90 \%$ of African Americans report that churches fulfill a wide variety of social roles in the community, and that churches have a positive influence in their lives. ${ }^{20}$

While social networks within churches are a valuable resource for congregants, clergy are often the most visible and trusted source of support within churches. ${ }^{21}$ With 
more than 400,000 ministers, priests, and rabbis actively serving in the United States, clergy represent a large body of professionals. They are involved in their communities, know their congregants well, and see them on a regular basis. Thus clergy are in a unique position to notice changes in behavior over time. Their roles as senior leaders of churches, their embodiment of important tenants of their faiths, and their formal roles as caregivers of their congregations also lend clergy considerable credibility, particularly within African American communities. Clergy are often seen as being deeply committed to their congregants and willing to honor desires for confidentiality. They typically receive some training in pastoral counseling methods. ${ }^{21}$ In addition, clergy do not typically charge fees for pastoral counseling services, require insurance, or have extensive paperwork requirements. ${ }^{18}$ Clergy represent an important front line resource for those seeking mental health or social services; for many adults who seek help with a mental illness, substance use problems, or personal issues, the first professional contacted is clergy, rather than mental health specialists. ${ }^{22,23}$

It is widely known that many people rely on clergy for various problems in their lives, but rates and correlates of use of clergy for alcohol problems remain unclear. While clergy are positioned to be an easily accessible source of support and services for alcohol misuse, qualitative research suggests that some individuals do not feel comfortable with taking issues related to alcohol misuse to their clergy. ${ }^{24}$ Reasons for not using clergy counseling services include shame, perceived lack of knowledge or skill on the part of the clergyperson, and availability of clergy time. ${ }^{24}$ To date there has been little population-level quantitative study of the use, or lack of use, of clergy services for individuals with alcohol-related problems.

To help improve the overall system of care for persons with alcohol-related problems, it is important to understand both specialty and nonspecialty service use. As nonspecialty service use is understudied, we sought to examine the prevalence of use of clergy services among those adults who received help for an alcohol use problem in the United States, as well as characteristics and correlates of individuals with alcohol-related problems who used clergy services compared to individuals who used other types of services. We also examined the degree to which individuals who receive help from the clergy receive other types of services as well. The results will contribute to a better understanding of the overall system of care for persons with alcohol problems and inform strategies for increasing service use.

\section{MATERIALS AND METHODS}

\section{Study Design}

This study used data from the 2001-2002 National Epidemiologic Survey on Alcohol and Related Conditions (NESARC), a nationally representative survey of 43,093 noninstitutionalized U.S. residents aged 18 years and older. Descriptions of the NESARC survey and sampling protocol are described in detail elsewhere. ${ }^{25,26}$ The NESARC was based on multistage sampling design, oversampling young adults, Hispanics, and Blacks to obtain reliable statistical estimation in these subpopulations, and to ensure appropriate representation of racial/ethnic groups. A sample of households and group living facilities was drawn based on U.S. census data, and one person was selected at random from the roster of eligible individuals living at each selected household. The overall response rate was $81 \%$, and all participants provided informed consent. Data were weighted at the individual and household levels and to adjust for oversampling and nonresponse on select demographic variables and adjusted to be representative of the U.S. population assessed during the 2000 census.

In the administration of this survey, U.S. Census Bureau workers, trained by National Institute on Alcohol Abuse and Alcoholism (NIAAA) staff, administered the Alcohol Use Disorders and Associated Disabilities Interview Schedule DSM-IV version (AUDADIS-IV). ${ }^{27}$ AUDADIS-IV is a structured interview designed for administration by trained lay interviewers. AUDADIS assesses 10 DSM-IV substance use disorders and has evidenced good-to-excellent reliability for the assessment of substance use disorders. ${ }^{27}$

\section{Measurement}

A series of questions on treatment utilization measured use of clergy services for alcohol use problems. The sample for the present analyses was restricted to those individuals who endorsed the question "Have you ever gone anywhere or seen anyone for a reason that was related in any way to your drinking - a physician, counselor, alcoholics anonymous, or any other community agency or professional?" ( $n=1,910)$. Respondents who endorsed this question were then asked about lifetime use of services for alcohol-related problems, including Alcoholics Anonymous/Narcotics Anonymous, inpatient wards, private physicians, and human service professionals (ie, psychiatrists, psychologists, and social workers), outpatient clinics, family or social services, detoxification, rehabilitation, emergency departments, halfway houses, employee assistance programs, crisis centers, and clergy (ie, clergyman, priest, or rabbi). The outcome of the current study was receiving clergy services for reasons related to drinking.

Several sociodemographic variables were assessed in this study. These included racial/ethnic groups (including nonHispanic White, Black, and Hispanic), gender (male and female), living area (urban/rural), marital status (married, separated/divorced/widowed, and never married), personal income (in dollars), age (in years), and employment status (employed, unemployed). Insurance status referred to current (at the time of taking the survey) private or public insurance (eg, medicare, medicaid, CHAMPUS, CHAMPVA, VA, or other military healthcare). It should 
be noted that data regarding insurance status at time of diagnosis and/or treatment are not available in the NESARC data set.

Several DSM-IV concordant clinical characteristics were also included in the current study. The AUDADIS instrument study queries respondents on the symptoms of AUDs (abuse and dependence) and other disorders described in the DSM-IV. The data from this symptom inventory were coded by NESARC study staff to indicate if respondents met criteria for alcohol abuse and/or alcohol dependence, according to the criteria set forth in the DSMIV. For the purposes of the present study, we created a variable for alcohol-related problems with three mutually exclusive categories, indicating which individuals had a lifetime diagnosis of alcohol abuse (without history of dependence), had a lifetime alcohol dependence (with or without abuse), or had no lifetime alcohol use disorder (this group likely including individuals with heavy or binge drinking, but without the negative consequences and psychological symptoms associated with AUDs). As prior research shows that psychiatric comorbidities are associated with higher rates of service utilization, the following DSMIV-defined psychiatric conditions were included in the analysis: major depressive disorder, anxiety disorders (ie, generalized anxiety disorder, social phobia, panic disorders, agoraphobia, and specific phobia), an Axis II personality disorder (ie, antisocial, avoidant, dependent, obsessive compulsive, paranoid, schizoid, and histrionic), and any non-nicotine lifetime drug use disorder (ie, marijuana, cocaine or crack, tranquilizers, stimulants, painkillers, other prescription drugs, heroin, inhalants or solvents, hallucinogens, and sedatives).

\section{Analysis}

Analyses were computed using SUDAAN Version 9.0 (RTI International, Research Triangle Park, North Carolina) in order to obtain properly adjusted standard errors based on the complex survey weights. This system implements a Taylor series linearization to adjust standard errors of estimates for complex survey sampling design effects including clustered data. Chi-square tests and simple logistic regressions were used to examine bivariate associations. Multivariable logistic regression analyses were used to identify factors associated with use of clergy services, while adjusting for other sociodemographic and clinical variables.

\section{RESULTS}

Of the 1,910 individuals who reported seeking treatment for alcohol use-related problems, $14.7 \%$ (95\% CI 12.8-16.8) reported using clergy services. The majority of those who used services from clergy also used professional services at some point; only .5\% used clergy services exclusively for their alcohol use-related problem. Chi-square tests (reported in Table 1) revealed a higher prevalence of clergy service use among individuals with alcohol dependence, an anxiety disorder, major depressive disorder, personality disorder, or other drug use disorder than among individuals without these diagnoses (all $p \leq .001$ ).

Similar trends emerged in multivariable logistic regression modeling (Table 2). Individuals who met criteria for major depressive and personality disorders were significantly more likely to report use of clergy services (adjusted odds ratio $[\mathrm{AOR}]=1.78$ and 1.73 , respectively), though the relations between anxiety disorders and drug use disorders with use of clergy services attenuated after adjustment for demographic characteristics and the other mental health conditions (AOR $=.98$ and 1.31, respectively). Persons with lifetime alcohol dependence (with or without abuse) were 4.83 times more likely to seek clergy services than those without an AUD. No statistically significant differences were observed between those without an AUD and a lifetime history of alcohol abuse (without dependence). Subsequent post hoc comparisons showed that individuals who met criteria for alcohol dependence (with or without abuse) were significantly more likely to report use of clergy services compared to individuals with lifetime alcohol abuse (without dependence; AOR $=2.70,95 \% \mathrm{CI}=$ 1.76-4.46).

Among the sociodemographic characteristics examined, we found that Black respondents had $68 \%$ greater odds of using clergy services for alcohol-related problems than White respondents, and individuals aged 35-54 had 62\% greater odds of using clergy services than individuals aged $18-34$

\section{DISCUSSION}

The majority of addiction services research focuses on specialty service but little is known about the nonspecialty sector of care, particularly clergy services. This study represents the most detailed study to date of clergy service use for alcohol-related problems. Notable strengths of this study include using a nationally representative communitybased sample, DSM-IV concordant diagnoses, and adjustments for other sociodemographic and clinical characteristics. Overall, we found that approximately $14.7 \%$ of service users for alcohol problems met with clergy. Although professional services are used more commonly, these findings show that clergy services are an important part of the overall system of care for persons with alcohol problems. Because the vast majority $(96.7 \%)$ of individuals who used clergy services also reported lifetime use of professional services, it is important that professional service providers and clergy effectively coordinate and integrate their support services. The system of care has the possibility of being enhanced when specialty and nonspecialty providers can make cross-sector referrals. However, previous research has shown that few clergy refer their clients to professional services. ${ }^{20}$ 
TABLE 1. Bivariate comparisons of individuals who used minister, clergy, or rabbi services and individuals who did not among those seeking treatment for alcohol use problems in the NESARC

\begin{tabular}{|c|c|c|c|c|}
\hline Characteristic & $\begin{array}{c}\text { Overall } \\
\text { sample } \\
(n=1,910) \%\end{array}$ & $\begin{array}{c}\text { Clergy } \\
\text { services } \\
(n=273) \%\end{array}$ & $\begin{array}{c}\text { No clergy } \\
\text { services } \\
(n=1,637) \%\end{array}$ & $\begin{array}{l}\text { Chi-square } \\
\text { test, } p \text {-value }\end{array}$ \\
\hline Sex: Female & 26.9 & 30.6 & 26.2 & $1.62, .21$ \\
\hline \multicolumn{5}{|l|}{ Race } \\
\hline White & 80.7 & 79.9 & 80.8 & $.84, .44$ \\
\hline Black & 9.7 & 12.0 & 9.3 & \\
\hline Hispanic & 9.6 & 8.1 & 9.9 & \\
\hline Living area: Urban & 30.8 & 31.4 & 30.7 & $.04, .84$ \\
\hline Marital status & & & & $.74, .48$ \\
\hline Married & 51.2 & 53.5 & 50.8 & \\
\hline Separated/widowed/divorced & 26.4 & 27.3 & 26.3 & \\
\hline Never married & 22.4 & 19.2 & 22.9 & \\
\hline Income & & & & $1.83, .15$ \\
\hline$\$ 70,000$ or more & 18.3 & 21.0 & 17.9 & \\
\hline$\$ 35,000-69,999$ & 30.5 & 29.4 & 30.7 & \\
\hline$\$ 20,000-34,999$ & 23.1 & 17.3 & 24.1 & \\
\hline$\$ 0-19,999$ & 28.1 & 32.4 & 27.4 & \\
\hline Age & & & & $3.55, .03$ \\
\hline 55 and over & 19.4 & 17.5 & 19.8 & \\
\hline $35-54$ & 54.0 & 62.3 & 52.5 & \\
\hline $18-34$ & 26.6 & 20.2 & 27.7 & \\
\hline Any insurance & 25.6 & 28.3 & 25.1 & $.79, .38$ \\
\hline Lifetime anxiety disorder & 29.4 & 41.7 & 27.3 & $11.57, .001$ \\
\hline Lifetime personality disorder & 34.8 & 51.9 & 31.9 & $20.85,<.001$ \\
\hline Lifetime major depressive disorder & 37.1 & 55.1 & 33.9 & $26.32,<.001$ \\
\hline Lifetime drug use disorder & 47.9 & 60.3 & 45.9 & $15.00,<.001$ \\
\hline Lifetime alcohol use disorder diagnosis & & & & $21.42,<.001$ \\
\hline None & 2.9 & .7 & 3.3 & \\
\hline Abuse (only) & 29.1 & 12.6 & 32.0 & \\
\hline Dependence (with or without abuse) & 68.0 & 86.7 & 64.8 & \\
\hline
\end{tabular}

Note: All percentages are weighted column percentages.

Black adults are more likely to use clergy services for alcohol use-related problems. This finding is consistent with previous research which indicates the centrality of religion and churches in Black American life ${ }^{20}$ and the significantly higher levels of religious service attendance among Black adults. ${ }^{28}$ Clergy may be an entryway for Blacks to engage in alcohol-related treatment. This is particularly important for Black Americans because of their overall underutilization of professional services.

Individuals who met criteria for alcohol dependence were more likely to have used clergy services for alcohol use-related problems than individuals who never met criteria or who only met criteria for alcohol abuse. This may in part reflect the fact that individuals who meet criteria for alcohol abuse by definition have experienced legal, occupational, and/or social problems due to their alcohol consumption, and may be more likely to enter treatment through the legal system, employee assistance programs, or social services. We also found that individuals with more psychopathology were more likely to have used clergy services for alcohol problems. Specifically, individuals with DSM-IV-defined major depressive disorder and individuals with a personality disorder were more likely to have sought the services of a clergy member. This suggests the importance of providing clergy with increased educational opportunities to understand these clinical disorders. Professional service providers can also benefit from a greater understanding of the spiritual needs of their clients and the types of resources that would be most beneficial.

\section{Limitations}

There are several limitations to this study. The analysis is cross-sectional, and based on lifetime measurements of mental health and substance use-related conditions. We 
TABLE 2. Weighted logistic regression of correlates of use of minister, clergy, or rabbi services among individuals seeking treatment for alcohol use problems in the NESARC $(N=1,910)$

\begin{tabular}{|c|c|c|}
\hline Factors & Unadjusted odds ratio $(95 \% \mathrm{CI})$ & Adjusted odds ratio $(95 \% \mathrm{CI})$ \\
\hline \multicolumn{3}{|l|}{ Sociodemographic characteristics } \\
\hline \multicolumn{3}{|l|}{ Sex } \\
\hline Males & 1.00 & 1.00 \\
\hline Female & $1.24(.90,1.71)$ & $1.03(.71,1.50)$ \\
\hline \multicolumn{3}{|l|}{ Race } \\
\hline White & 1.00 & 1.00 \\
\hline Black & $1.30(.82,2.06)$ & $1.68(1.01,2.79)$ \\
\hline Hispanic & $.84(.48,1.44)$ & $1.07(.60,1.92)$ \\
\hline \multicolumn{3}{|l|}{ Urbanicity } \\
\hline Rural & 1.00 & 1.00 \\
\hline Urban & $1.03(.74,1.44)$ & $1.09(.76,1.56)$ \\
\hline \multicolumn{3}{|l|}{ Marital status } \\
\hline Never married & 1.00 & 1.00 \\
\hline Married & $1.26(.84,1.88)$ & $1.16(.75,1.79)$ \\
\hline Separated/divorced/widowed & $1.24(.81,1.88)$ & $.88(.55,1.41)$ \\
\hline \multicolumn{3}{|l|}{ Income } \\
\hline$\$ 70,000$ or more & 1.00 & 1.00 \\
\hline$\$ 35,000-69,999$ & $.81(.50,1.34)$ & $.88(.52,1.48)$ \\
\hline$\$ 20,000-34,999$ & $.61(.35,1.05)$ & $.62(.36,1.06)$ \\
\hline$\$ 0-19,999$ & $1.01(.63,1.60)$ & $.85(.50,1.45)$ \\
\hline \multicolumn{3}{|l|}{ Insurance } \\
\hline None & 1.00 & 1.00 \\
\hline Any & $1.18(.83,1.67)$ & $1.07(.66,1.74)$ \\
\hline \multicolumn{3}{|l|}{ Age } \\
\hline $18-34$ & 1.00 & 1.00 \\
\hline $35-54$ & $1.62(1.09,2.43)$ & $1.62(1.05,2.51)$ \\
\hline 55 and over & $1.21(.74,1.99)$ & $1.59(.85,2.97)$ \\
\hline \multicolumn{3}{|l|}{ Clinical characteristics } \\
\hline \multicolumn{3}{|l|}{ Lifetime alcohol use disorder diagnosis } \\
\hline None & 1.00 & 1.00 \\
\hline Abuse (only) & $2.00(.60,6.67)$ & $1.79(.48,6.61)$ \\
\hline Dependence (with or without abuse) & $6.78(1.94,23.74)$ & $4.83(1.25,18.72)$ \\
\hline \multicolumn{3}{|l|}{ Lifetime major depressive disorder } \\
\hline No & 1.00 & 1.00 \\
\hline Yes & $2.49(1.81,3.42)$ & $1.78(1.22,2.61)$ \\
\hline \multicolumn{3}{|l|}{ Lifetime personality disorder } \\
\hline No & 1.00 & 1.00 \\
\hline Yes & $2.30(1.68,3.17)$ & $1.73(1.19,2.50)$ \\
\hline \multicolumn{3}{|l|}{ Lifetime drug use disorder } \\
\hline No & 1.00 & 1.00 \\
\hline Yes & $1.83(1.36,2.47)$ & $1.31(.93,1.85)$ \\
\hline \multicolumn{3}{|l|}{ Lifetime anxiety disorder } \\
\hline No & 1.00 & 1.00 \\
\hline Yes & $1.90(1.37,2.64)$ & $.98(.65,1.47)$ \\
\hline
\end{tabular}

Note: CI stands for Confidence Interval. Values in bold are statistically significant based on a $95 \%$ CI that does not bound the value 1.0 .

did not have data on the temporal ordering of service use to help determine what types of services were used first. While individuals who had met criteria for alcohol dependence were more likely to report use of clergy services, it is also unknown if they sought this service during the same period that they met criteria. In addition to using lifetime measurements, we have used DSM-IV criteria to determine the presence of mental health and substance use-related conditions. While this method has the advantage of relying on well accepted, reliable, and clinically valid measurement 
tools, the study was not able to examine less severe mental health issues and conditions that may also be improved through treatment. A measure of religious beliefs was not available in the present dataset. Future research should explore religious beliefs as a mediator of the association of demographic characteristics with clergy service use. In particular, differences in religious beliefs and affiliation may explain the race group differences observed in this study given the higher rates of church attendance among Black Americans. ${ }^{28}$ Despite these limitations, the present findings are important because this is one of very few studies to examine correlates of clergy service use for alcohol-related problems.

\section{Implications and Future Research}

This study revealed that approximately one in seven persons in the United States who used services for alcohol problems met with a member of the clergy. Further research on patient preferences for treatment, particularly including spiritual needs, can help us understand the overall potential role of clergy within the system of care for alcohol-related problems. Additional research is also needed to better understand the extent to which clergy are meeting the complex needs of this population.

This study revealed that those with alcohol dependence are more likely to meet with clergy than those without. Religious leaders may benefit from training on identifying signs of problem drinking among parishioners, intervening with individuals exhibiting signs of problem drinking, and reducing stigma and other barriers to professional care. Training for clergy may be particularly helpful for determining when a congregant should be referred for professional services and what type of referral is required (eg, detoxification for physical dependence to alcohol, emergency services for suicidal behaviors, or violent tendencies toward others). Professional service providers may also consider collaboration with clergy around problems that involve issues that call into question basic life beliefs ${ }^{24,29}$ (eg, death, illness, and disability) and may also exacerbate alcohol abuse. Future research is needed to explore the feasibility and effectiveness of such outreach and collaborative efforts.

\section{Declaration of Interest}

The authors report no conflicts of interest. The authors alone are responsible for the content and writing of the paper.

\section{REFERENCES}

1. Nelson DE, Naimi TS, Brewer RD, et al. State alcohol-use estimates among youth and adults, 1993-2005. Am J Prev Med. 2009;36:218224.

2. Naimi TS, Brewer RD, Mokdad A, et al. Binge drinking among US adults. JAMA. 2003;289:70-75.

3. American Psychiatric Association. Diagnostic and Statistical Manual of Mental Disorders, Fourth Edition (Text Revision; DSM-IV-TR). Arlington, VA: American Psychiatric Association, Inc.; 2000.
4. Baglietto L, English DR, Hopper JL, et al. Average volume of alcohol consumed, type of beverage, drinking pattern and the risk of death from all causes. Alcohol Alcohol. 2006;41:664-671.

5. Chermack ST, Blow FC. Violence among individuals in substance abuse treatment: The role of alcohol and cocaine consumption. Drug Alcohol Depend. 2002;66:29-37.

6. Chander G, Lau B, Moore RD. Hazardous alcohol use: A risk factor for non-adherence and lack of suppression in HIV infection. $J$ Acquir Immune Defic Syndr. 2006;43:411-417.

7. Dawson DA. Alcohol consumption, alcohol dependence, and allcause mortality. Alcohol Clin Exp Res. 2000;24:72-81.

8. Dawson DA, Grant BF, Stinson FS, et al. Psychopathology associated with drinking and alcohol use disorders in the college and general adult populations. Drug Alcohol Depend. 2005;77:139-150.

9. Di Castelnuovo A, Costanzo S, Bagnardi V, et al. Alcohol dosing and total mortality in men and women: An updated meta-analysis of 34 prospective studies. Arch Intern Med. 2006;166:2437-2445.

10. Doshi A, Boudreaux ED, Wang N, et al. National study of US emergency department visits for attempted suicide and self-inflicted injury, 1997-2001. Ann Emerg Med. 2005;46:369-375.

11. Gmel G, Givel JC, Yersin B, et al. Injury and repeated injury - what is the link with acute consumption, binge drinking and chronic heavy alcohol use? Swiss Med Wkly. 2007;137:642-648.

12. Miller WR, Wilbourne PL. Mesa Grande: A methodological analysis of clinical trials of treatment for alcohol use disorders. Addiction. 2002;97:265-277.

13. Dawson DA, Grant BF, Stinson FS, et al. Estimating the effect of help-seeking on achieving recovery from alcohol dependence. Addiction. 2006;101:824-834.

14. Wang PS, Berglund P, Olfson M, et al. Failure and delay in initial treatment contact after first onset of mental disorders in the national comorbidity survey replication. Arch Gen Psychiatry. 2005;62:603-613.

15. Saunders SM, Zygowicz KM, D'Angelo BR. Person-related and treatment-related barriers to alcohol treatment. J Subs Abuse Treat. 2006;30:261-270.

16. Grant BF. Barriers to alcoholism treatment: Reasons for not seeking treatment in a general population sample. J Stud Alcohol. 1997;58:365-371.

17. Hatchett BF, Miller JB, Holmes KY, et al. The clergy: A valuable resource for church members with alcohol problems. $J$ Pastoral Care Counsel. 2007;61:39-46.

18. Taylor RJ, Ellison CG, Chatters LM, et al. Mental health services in faith communities: The role of clergy in black churches. Soc Work. 2000;45:73-87.

19. Krause N. Exploring race differences in a comprehensive battery of church-based social support measures. Rev Relig Res. 2002:126-149.

20. Taylor RJ, Chatters LM, Levin JS. Religion in the Lives of African Americans: Social, Psychological, and Health Perspectives. Thousand Oaks: Sage Publications; 2004.

21. Krause N. Exploring race differences in the relationship between social interaction with the clergy and feelings of self-worth in late life. Sociol Relig. 2003:183-205.

22. Wang PS, Berglund PA, Kessler RC. Patterns and correlates of contacting clergy for mental disorders in the United States. Health Serv Res. 2003;38:647.

23. Chalfant HP, Heller PL, Roberts A, et al. The clergy as a resource for those encountering psychological distress. Rev Relig Res. 1990:305-313.

24. Mattis JS, Mitchell N, Zapata A, et al. Uses of ministerial support by African Americans: A focus group study. Am J Orthopsychiatry. 2007;77:249-258.

25. Grant BF, Dawson DA. Introduction to the national epidemiologic survey on alcohol and related conditions. Alcohol Res Health. 2006;29:74-78.

26. Grant BF, Dawson DA, Stinson FS, et al. The 12-month prevalence and trends in DSM-IV alcohol abuse and dependence: United States, 1991-1992 and 2001-2002. Drug Alcohol Depend. 2004;74:223-234. 
27. Grant BF, Dawson DA, Stinson FS, et al. The Alcohol Use Disorder and Associated Disabilities Interview Schedule-IV (AUDADIS-IV): Reliability of alcohol consumption, tobacco use, family history of depression and psychiatric diagnostic modules in a general population sample. Drug Alcohol Depend. 2003;71:7-16.

28. Taylor RJ, Chatters LM, Jayakody RT, et al. Black and white differences in religious participation: A multi-sample comparison. J Sci Study Relig. 1996;35:403-410.

29. Neighbors HW, Musick MA, Williams DR. The African American minister as a source of help for serious personal crises: Bridge or barrier to mental health care? Health Educ Behav. 1998;25:759777. 